\title{
The Difficulties Encountered by Pediatric Cochlear Implant Patients and Their Parents during the COVID-19 Pandemic
}

\author{
Laila M. Telmesani $^{\mathrm{a}}$ Nithreen M. Said ${ }^{\mathrm{b}}$ Mahmoud M. Mahrous ${ }^{\mathrm{c} d}$ \\ Danah F. Alrusayyis ${ }^{e}$ \\ aOtorhinolaryngology Department, Faculty of Medicine, Imam Abdulrahman Bin Faisal University, Dammam, \\ Saudi Arabia; ${ }^{b}$ Audiovestibular Medicine Unit, Otorhinolaryngology Department, Faculty of Medicine, Imam \\ Abdulrahman Bin Faisal University, Dammam, Saudi Arabia; 'Audio-Vestibular Medicine Unit, Otorhinolaryngology \\ Department, King Fahad Hospital of University, Imam Abdulrahman Bin Faisal University, Dammam, Saudi Arabia; \\ ${ }^{\mathrm{d} A u d i o-V e s t i b u l a r}$ Medicine Unit, Otorhinolaryngology Department, Faculty of Medicine, Ain Shams University, Cairo,

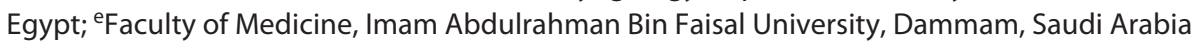

\section{Keywords}

COVID-19 $\cdot$ Telemedicine $\cdot$ Remote programing $\cdot$ Cochlear implant · Questionnaire

\begin{abstract}
Introduction: The daily escalation in incidence and mortality caused by Coronavirus disease (COVID-19) has mandated forced curfew in our country (same as many other countries) to limit the spread of infection. This is predicted to have a more negative impact on cochlear implant $(\mathrm{Cl})$ patients since this group of patients needs a unique type of psychological, medical, and technical care in addition to a daily rehabilitation program. Methods: A cross-sectional study based on Arabic questionnaire that looked into the collateral consequences of COVID-19 on the pediatric $\mathrm{Cl}$ patients. The questionnaire was designed to highlight different problems such as exposure to head trauma or ear infection, difficulties in device maintenance and getting spare parts, impacts of the delay of programing or switch on appointments, and the impacts of missing rehabilitation sessions. Different ways of management of these problems are presented and dis-
\end{abstract}

cussed. Results: A total of 174 parents responded to the questionnaire. The main problem met by the patients was missing their device programing and rehabilitation sessions. Many children had device maintenance and spare parts problems. Virtual clinics were helpful in solving different problems. Additionally, children who needed device programing were scheduled for remote programing sessions. Conclusion: Although the inevitable consequences of the COVID-19 pandemic are catastrophic, they are forcing the medical field to explore new opportunities by sitting up an infrastructure for future usage of telemedicine. Telemedicine is cost-effective and more convenient and enables health-care providers to be immune to future circumstances.

(c) 2021 S. Karger AG, Basel

\section{Introduction}

Coronavirus disease (COVID-19) emerged in China and spread rapidly throughout the country and, subsequently, to other countries. Due to the severity of this outbreak and the potential of spreading on an international karger@karger.com www.karger.com/aud

(C) 2021 S. Karger AG, Base

Karger"
Correspondence to:

Nithreen M. Said, nithreens@yahoo.com 
scale, the WHO declared a global health emergency on 31 January 2020. Subsequently, on 11 March 2020, they declared it a pandemic situation. Most nations are currently making efforts to prevent the further spreading of this potentially deadly virus by implementing preventive and control strategies [Kuldeep et al., 2020].

COVID-19 has drastically affected health care across the globe. Providing health care during this pandemic appeared to be challenging as health-care services are being disrupted due to inadequate protective gears, lockdown, risk of infection spread to patients and medical practitioners [Golinelli et al., 2020]. There was a need to provide diagnosis, treatment, monitoring, and followups for certain patients during the pandemic [Bokolo, 2020].

Providing services for cochlear implant (CI) users was also affected during the COVID-19 pandemic. CI users often require regular visits to audiology clinics to optimize patient's benefits from the CI, which include programing adjustments, monitoring of performance through speech perception testing, counseling regarding expectations, and communication strategies in addition to introduction and demonstration of additional equipment, such as device wearing options and use of assistive listening devices [Heidi et al., 2019].

Moreover, CI patients need to have their regular rehabilitation sessions, especially in infants and young children. Intensive individualized habilitation (intervention for patients who had never heard before) and rehabilitation (intervention for patients who are learning to hear again) allows for optimal performance for all recipients [Matthew et al., 2016]. An additional problem for CI patients is their frequent need to spare parts and maintenance related to their CI device.

Therefore, the COVID-19 pandemic has radically and quickly altered how medical practitioners provide care to patients. Medical centers are now responding to COVID-19 through rapid adoption of digital tools and technologies such as telemedicine and virtual care. Telemedicine refers to the delivery of health-care services from distance - without direct physical contact with the patient [Bokolo, 2020].

As the pandemic had affected all the services provided to our pediatric CI patients, and they faced many challenges when there was limited access to our clinics and services. Hence, the authors designed a descriptive questionnaire to address the problems that faced our pediatric CI patients during the COVID-19 pandemic and to highlight the role of virtual clinics and telemedicine in solving these problems.

Cochlear Implant Patient's Troubles

during COVID-19 Pandemic

\section{Method}

The study protocol was approved by the Imam Abdulrahman Bin Faisal University Institutional Review Board (IRB-2020-01170) prior to subject enrollment, and informed consent was obtained from each subject prior to initiation of any study-related activities. 174 pediatric CI users were included in the study. All of them were implanted at King Fahd Hospital of the University (KFHU) with regular follow-up appointments. Patients were using cochlear Nucleus, Medel or Advanced Bionics devices. This study was performed in a period of 3 months from April 2020 to June 2020.

\section{Questionnaire Development}

A descriptive original questionnaire was developed by the authors to highlight the problems met by $\mathrm{CI}$ children during the $\mathrm{CO}$ VID-19 pandemic and the lockdown period. The questionnaire was conducted for the patient's parents over the phone by a medical student. The questionnaire consists of 40 questions that were prepared in English language and translated into Arabic language to be understood by the respondents. Then, backward translation of the responses was done from Arabic to English to be able to analyze and present the data. First, 14 questions focused on the respondent information, child information, and duration of rehabilitation with the CI device. The remaining questions focused on 4 categories:

a Exposure to medical issues related to the implanted ear and the medical care that was provided to the child

b Difficulties in device maintenance and getting spare parts, specifying which spare part was needed and the way they could get the needed part

c The impacts of the delay of programing or switch on appointments and the way that this problem was solved

d The impacts of missing rehabilitation sessions focusing on effects on child behavior and communication skills in addition to the daily wearing hours of the device

The questions were provided either in the form of dichotomous question (yes/no answer) or rating scale questions (1-5 scaling) in which parents were given options that range from 1 (strongly disagree) to 5 (strongly agree). Questions related to spare parts and maintenance of the device were given in the form of multiple choice questions where the patient can choose one or more answer.

For validity testing process, the questionnaire was completed by randomly selected 7 respondents. The responses were analyzed by the authors and minor revisions were performed to the questionnaire. The question about missing switch on the session was rewritten and clarified more to the respondents. Additionally, we stressed on reporting the problems that were faced during the $\mathrm{CO}$ VID-19 pandemic only. The questionnaire responses were analyzed to highlight the problems met by the patients during the pandemic. Additionally, the different solutions that were provided by the CI team to overcome these problems were analyzed and presented.

\section{Virtual Clinics}

The CI team including the surgeon, audiovestibular medicine physicians, and speech and language pathologists contacted many patients during the lockdown through telephone calls. After the end of the lockdown period ENT, outpatient clinics worked only as telephone call clinics and patients without urgent medical or surgical insults were not allowed to attend the clinics physically. 
Table 1. Descriptive data of the study subjects

\begin{tabular}{|c|c|c|}
\hline Personal and child data & $N$ & $\%$ \\
\hline \multicolumn{3}{|l|}{ Family size } \\
\hline$<5$ persons & 101 & 58.0 \\
\hline$>5$ persons & 73 & 42.0 \\
\hline \multicolumn{3}{|l|}{ Contacted person } \\
\hline Father & 101 & 58.0 \\
\hline Mother & 70 & 40.2 \\
\hline Relative & 3 & 1.7 \\
\hline \multicolumn{3}{|l|}{ Child gender } \\
\hline Male & 92 & 52.9 \\
\hline Female & 82 & 47.1 \\
\hline \multicolumn{3}{|c|}{ Age at time of surgery, years } \\
\hline Mean & 3.38 & \\
\hline $\mathrm{SD}$ & 2.12 & \\
\hline \multicolumn{3}{|l|}{ Current age, years } \\
\hline Mean & 7.17 & \\
\hline $\mathrm{SD}$ & 3.16 & \\
\hline \multicolumn{3}{|c|}{ Duration of implant use, years } \\
\hline Mean & 3.93 & \\
\hline $\mathrm{SD}$ & 2.57 & \\
\hline \multicolumn{3}{|c|}{ Classification of duration since implantation, months } \\
\hline $1-3$ & 3 & 1.7 \\
\hline $3-6$ & 4 & 2.3 \\
\hline $6-9$ & 2 & 1.1 \\
\hline $9-12$ & 8 & 4.6 \\
\hline $12-24$ & 24 & 13.8 \\
\hline $24-36$ & 23 & 13.2 \\
\hline$>36$ & 110 & 63.2 \\
\hline \multicolumn{3}{|l|}{ CI device } \\
\hline Cochlear & 105 & 60.3 \\
\hline Medel & 62 & 35.6 \\
\hline Advanced Bionics & 7 & 4 \\
\hline Unilateral CI & 140 & 80.5 \\
\hline Bilateral CI & 34 & 19.5 \\
\hline
\end{tabular}

CI, cochlear implant.

Workplace and Equipment

As all outpatient clinics at the hospital were closed due COVID-19 crisis, the CI programing was conducted at a remote location outside the hospital (at each CI company). All preventive measures for avoidance spread of COVID-19 were strictly applied at the workplace. Speech processors were remotely programed by the audiovestibular medicine physicians using one of the videoconferencing software packages. Zoom software was used to program Cochlear company patients, Cisco Webex software was used for Medel, and Team viewer software was used for Advanced Bionics patients.

Each remote workplace location was equipped with programing software, the programing pod, and cable. Custom sound version 5.2 was used to program patients using cochlear device. Maestro version 8 was used to program patients using Medel device. Sound Wave version 3.2 was used for programing of Advanced Bionics patients. The company engineer in the workplace location connects the device for the patient and allows the audiologist to
Table 2. Exposure to medical issues related to the implanted ear during the pandemic

\begin{tabular}{lll}
\hline Medical problem & $N$ & $\%$ \\
\hline $\begin{array}{l}\text { Child had ear infection during lockdown period } \\
\quad\end{array}$ & 4 & 2.3 \\
$\quad$ Yes & 170 & 97.7 \\
$\quad$ No & 4 & 100.0 \\
Went to hospital to treat the infection & & \\
$\quad$ Yes & 1 & 25.0 \\
Consulted CI surgeon for given treatment & 3 & 75.0 \\
$\quad$ Yes & & \\
$\quad$ No & 3 & 75.0 \\
Treatment received & 1 & 25.0 \\
$\quad$ Antibiotics only & \\
$\quad$ Antibiotics with anti-inflammatory drugs & 2.3 \\
Child exposed to head trauma during the lockdown & 4 & \\
$\quad$ Yes & 170 & 97.7 \\
$\quad$ No & & \\
Went to hospital due to the head trauma & 1 & 25 \\
$\quad$ Yes & 3 & 75 \\
$\quad$ No & & \\
Consulted the surgeon for management & 1 & 25.0 \\
$\quad$ Yes & 3 & 75.0 \\
$\quad$ No & & \\
Affected device function & 0 & 0.0 \\
$\quad$ Yes & 4 & 100 \\
$\quad$ No & & \\
\hline CI, cochlear implant. & & \\
\hline
\end{tabular}

control the programing software remotely. Titan (Interacoustics) tympanometry device was used to elicit electric stapedial reflex thresholds when needed.

Data Analysis

After data were extracted, it was revised, coded, and fed to statistical software IBM SPSS version 22 (SPSS, Inc., Chicago, IL, USA). Descriptive analysis based on frequency and percent distribution was done for all variables including participants' personal data, medical problems to the implanted ear, spares and supplies availability, company role, and communication methods with treating staff.

\section{Results}

In total 223 pediatric CI users were contacted by a medical student, and 174 parents responded to our questionnaire. The respondents were either mother or father of the child, and only 3 respondents were relatives taking care of the child (uncle, aunt, or grandfather). The age of the children included in the study ranged between 2 and 17 years. They were 92 boys and 82 girls. 105 patients were using cochlear Nucleus device, 62 patients were using Medel, 
and 7 patients were using Advanced Bionics CI. Thirtyfour patients had bilateral implantation. The duration of use of cochlear implantation calculated from the time of surgery was variable and ranged between 0 and 11.5 years of use. Most of them were old users for $>36$ months. Table 1 shows the descriptive data for the study subjects.

\section{Analysis of the Four Aspects of the Questionnaire}

Revealed the Following Results

Exposure to Medical Issues Related to the Implanted

Ear

Table 2 demonstrates medical issues happened to CI patients during the lockdown period. Only 4 children (2.3\%) had ear infection, and all of them sought immediate medical care in a nearby hospital. However, only 1 caregiver has consulted the CI team (surgeon), supervising the child's case for proper management. Treatment received included oral antibiotics (3 children), while 1 child was given oral antibiotics and anti-inflammatory drugs. Likewise, 4 children (2.3\%) were exposed to head trauma as a result of household activities, and only one of them needed medical checkup due to the development of a hematoma over the receiver stimulator unit. The surgeon again was consulted in the management of that patient, and the device function was not affected. In general, all children health condition was stable during lockdown.

\section{Difficulties in Device Maintenance and Getting Spare Parts}

Eighty-nine (51.1\%) patients reported that they had difficulties in getting the spare parts during the lockdown. The most commonly needed spare parts were cables and batteries. Table 3 shows the most commonly reported problems and needed spare parts. Forty-three (19.5\%) subjects needed $>1$ spare part during the lockdown period (shown in Fig. 1).

Home delivery of the spare parts was arranged by different companies. Sixty-one subjects (35.1\%) did orders to get spare parts at the time of the lockdown. Additionally, educational and technical support videos were provided by different $\mathrm{CI}$ companies to solve this issue to the families. Sixty-eight (39.1\%) patients got benefit from those videos, 14 (8\%) patients did not follow the videos, and $92(52.9 \%)$ patients were not aware about the educational videos (shown in Table 3 ).

The Impacts of Delayed Programing or Switch on

Appointments

Eighty-one patients out of 174 missed programing appointments. Five patients managed to get permission for
Table 3. Needed spare parts and company role in providing services during the lockdown period

\begin{tabular}{|c|c|c|}
\hline Needed spare parts and accessories & $N$ & $\%$ \\
\hline \multicolumn{3}{|l|}{ Batteries } \\
\hline Not needed at all & 6 & 9.8 \\
\hline Easy to find & 16 & 26.2 \\
\hline Difficult to find & 34 & 55.7 \\
\hline Not available at all & 5 & 8.2 \\
\hline \multicolumn{3}{|l|}{ Cables } \\
\hline Not needed at all & 13 & 21.3 \\
\hline Easy to find & 12 & 19.7 \\
\hline Difficult to find & 30 & 49.2 \\
\hline Not available at all & 6 & 9.8 \\
\hline \multicolumn{3}{|l|}{ Main processing unit } \\
\hline Not needed at all & 32 & 52.5 \\
\hline Easy to find & 8 & 13.1 \\
\hline Difficult to find & 15 & 24.6 \\
\hline Not available at all & 6 & 9.8 \\
\hline \multicolumn{3}{|l|}{ Dryer } \\
\hline Not needed at all & 37 & 60.7 \\
\hline Easy to find & 13 & 21.3 \\
\hline Difficult to find & 8 & 13.1 \\
\hline Not available at all & 3 & 4.9 \\
\hline \multicolumn{3}{|l|}{ Maget } \\
\hline Not needed at all & 32 & 52.5 \\
\hline Easy to find & 8 & 13.1 \\
\hline Difficult to find & 17 & 27.9 \\
\hline Not available at all & 4 & 6.6 \\
\hline \multicolumn{3}{|l|}{ Voice filters } \\
\hline Not needed at all & 26 & 42.6 \\
\hline Easy to find & 11 & 18.0 \\
\hline Difficult to find & 11 & 18.0 \\
\hline Not available at all & 13 & 21.3 \\
\hline \multicolumn{3}{|l|}{ Protective covers } \\
\hline Not needed at all & 27 & 44.3 \\
\hline Easy to find & 8 & 13.1 \\
\hline Difficult to find & 12 & 19.7 \\
\hline Not available at all & 14 & 23.0 \\
\hline \multicolumn{3}{|l|}{ Other accessories (e.g., ear hooks) } \\
\hline Not needed at all & 36 & 59.0 \\
\hline Easy to find & 3 & 4.9 \\
\hline Difficult to find & 11 & 18.0 \\
\hline Not available at all & 11 & 18.0 \\
\hline \multicolumn{3}{|c|}{$\begin{array}{l}\text { Benefit from educational videos and contact with technical } \\
\text { support in dealing with spare parts properly }\end{array}$} \\
\hline No & 14 & 8.0 \\
\hline Yes & 68 & 39.1 \\
\hline Did not received any videos & 92 & 52.9 \\
\hline \multicolumn{3}{|c|}{$\begin{array}{l}\text { Did you order spare parts from the support company during the } \\
\text { lockdown? }\end{array}$} \\
\hline No & 113 & 64.9 \\
\hline Yes & 61 & 35.1 \\
\hline
\end{tabular}

Audiol Neurotol 2022;27:48-55

DOI: $10.1159 / 000517148$ 
Fig. 1. Combined spare parts problems during the lockdown.

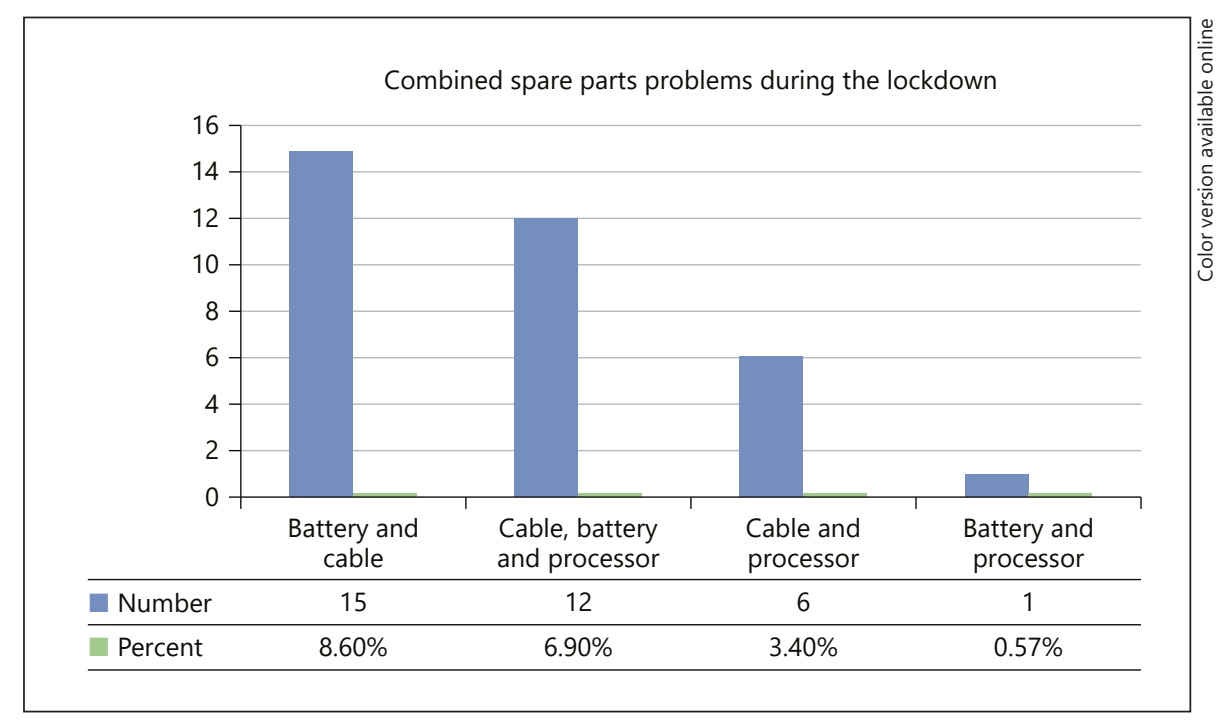

Fig. 2. Reasons for scheduling telepro-

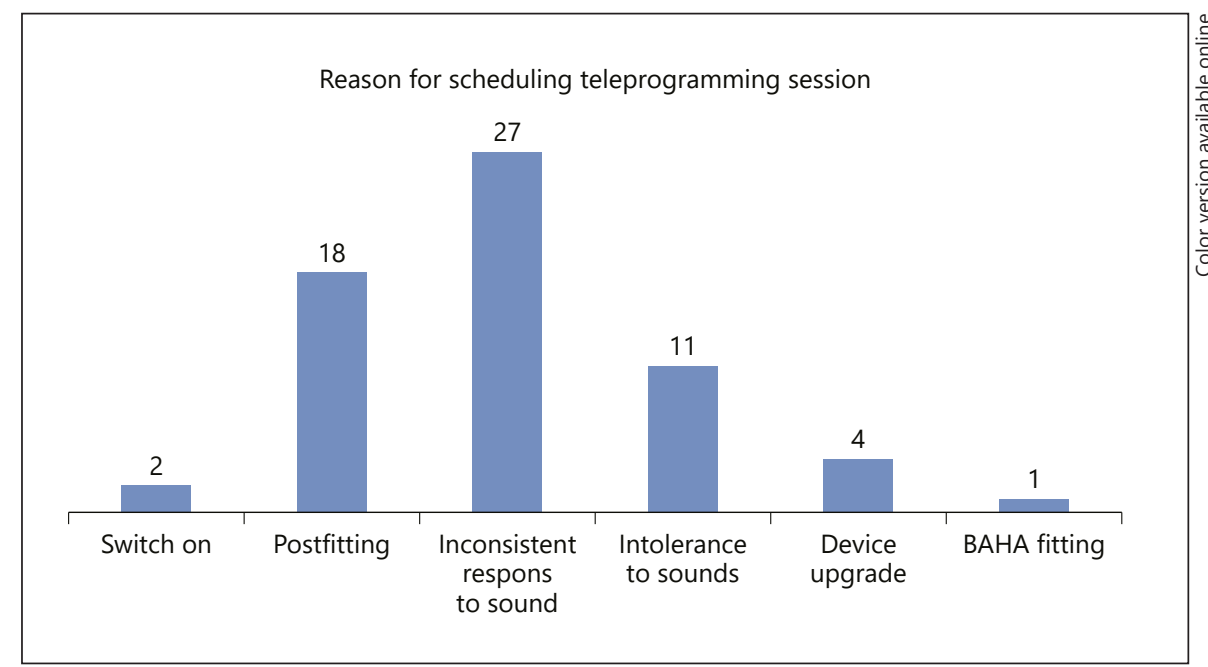
graming session.

going out during the lockdown for remote programing. They were scheduled at different days starting at April 2, 2020 till the end of May 2020. Even though the lockdown period ended on May 31, 2020, we continued to provide remote switch on and programing as we were not allowed to bring elective patients to the clinics. Remote programing was scheduled for patients who needed switch on or if they have hearing problem and needed programing. Most of the patients were contacted after opening of telephone call clinics. Sixty-three (36 cochlear users, $26 \mathrm{Me}-$ del users, and $1 \mathrm{AB}$ user) patients needed remote programing, and the rest reported no problem in hearing.

Figure 2 presents the reasons for scheduling the patients to teleprograming sessions. Two patients were implanted just before the lockdown, so they needed switch on sessions and a third patient needed BAHA fitting. Eighteen patients were recently fitted with CI and missed the post-fitting follow-up sessions, so they were scheduled for teleprograming sessions. The rest of the patients had problems in hearing either in the form of inconsistent response to some sounds or intolerance to some loud sounds, so they were scheduled to adjust their maps. Four patients needed urgent upgrade to their old malfunctioning devices. Two of them were upgraded from Cochlear Nucleus 5 to Kanzo device, and 2 patients were upgraded from Opus 2 to Rondo2 device. Electric Stapedial reflex threshold measurement was performed remotely for 4 Medel users to confirm map comfort levels.

The patients who received remote programing sessions were contacted again after 2 weeks to confirm that they have 
Table 4. Effect of lockdown on communication skills, interactive activities, and on device wearing hours

\begin{tabular}{|c|c|c|c|c|c|}
\hline Domain & Items & Min & Max & Mean & $\mathrm{SD}$ \\
\hline \multirow[t]{4}{*}{ Negative impact on the child } & Difficulty in communicating with my child & 1 & 5 & 2.2 & 1.6 \\
\hline & Engagement in interactive activities, such as talking and suggesting as before & 1 & 5 & 1.8 & 1.3 \\
\hline & My child may go into isolation if the lockdown continues for longer than expected & 1 & 5 & 1.6 & 1.3 \\
\hline & & & & $\mathrm{n}$ & $\%$ \\
\hline \multirow{2}{*}{ Wears hours of the device } & Reduced & & & 13 & 7.5 \\
\hline & Increased & & & 49 & 28.2 \\
\hline
\end{tabular}

no further problems. A follow-up remote programing session was done for the 2 patients who had the first switch on and for 6 subjects who needed further adjustments.

The Impacts of Missing Rehabilitation Session

Sixty-seven patients were contacted by our speech and language pathologists through virtual clinics during the pandemic. Video recordings for the children were sent by the parents to enable the speech pathologists to follow their performance and speech and language development. Many parents reported that the children rehabilitation was negatively affected during the pandemic. This negative effect was apparent mainly in their communication skills and ability of engagement in interactive activities. In respect to device wearing hours, most of the children showed no change in wearing hours, 49 children (28\%) showed increase in the wearing hours, and only 13 patients (8\%) reported less wearing hours of their devices (shown in Table 4).

\section{Discussion}

With the start of the COVID-19 pandemic in March 2020, outpatient departments in KFHU were stopped. CI operations like all other elective surgeries have also been discontinued and postponed. Consequently, the access to all the services of the CI unit (surgeons, audiology physicians and speech and language pathologists) has been delayed for hard of hearing patients especially during the complete lockdown period.

Patients included in the present study were all implanted in the KFHU CI unit. According to our protocol, postoperative rehabilitation of CI patients include medical care, technical controls, step-by-step optimization of the CI processor setting, intensive hearing-speech therapy, audiometric hearing and speech tests, counseling for the patient, further training in the use of the CI system (care, maintenance, and error detection), and in the use of additional devices. So, we distributed our questionnaire to highlight the impact of the pandemic on different services provided to CI patients.

In the first part of the questionnaire, we analyzed the exposure to medical issues related to the implanted ear. Only 8 (4.6\%) children out of 174 patients had a history of either mild ear infection or minimal head trauma with no effect on device function or performance. CI surgery has been well-established as a relatively safe and very effective auditory rehabilitation procedure. Well-informed surgical design and careful device fixation can minimize complications related to scalp flap infections and implant device exposure, as reported by Jiang et al. [2017].

The second part of the questionnaire was focused on the need for spare parts and device maintenance. The most commonly needed spare parts are the cables and the batteries. Thirty-four (19.5\%) subjects needed $>1$ spare part. These problems caused an additional burden on the parents, especially in the lockdown period and affected their children performance, as not all of the parents had spare parts at home. It is reported in the literature that any breakdown of the CI processor or temporary discontinuation of speech processor usage is strongly correlated with expected outcomes in CI children [Truy et al., 1998]. To solve this issue, the CI team contacted different CI companies and they arranged home delivery services for the spare parts. Although many educational videos were provided to help the parents to deal with spare part and device maintenance, only few subjects $(37.4 \%)$ could follow these videos. Consequently, our team added more efforts to contact the fam- 
ilies through phone or video calls to guide them to solve device problems.

The third problem highlighted by the questionnaire was the access to postoperative programing of the speech processors. Speech processor programing and assessment of speech perception performance must be optimized to get the best results and to evaluate and determine the course of rehabilitation of CI patients [Truy et al., 1998]. Consequently, the regular follow-up visits for assessment of performance and adjusting the processor programing are crucial to the patients.

In our study, 81 children missed their regular followup appointments and parents expressed their worries about the effect of missing these appointments on children performance. The COVID-19 pandemic has forced all health-care systems, hospitals, and clinics to rapidly implement telehealth services, and delivery of patient care was totally changed. Previous researchers studied various remote applications for CI users, such as intraoperative testing [Shapiro et al., 2008] and programing [Ramos et al., 2009; McElveen et al., 2010; Wesarg et al., 2010; Hughes et al., 2012; Botros et al., 2013]. Additionally, Goehring et al. [2012] and de Graaff et al. [2016] investigated the use of telehealth to measure speech recognition abilities in quiet and in noise for CI users. They reported that remote testing and programing is time- and cost-saving for both the audiologist and patient.

So, we started to apply telehealth technology in providing the programing sessions for our patients giving priority to recently implanted patients or recently fitted subjects. Moreover, remote programing was performed for subjects who had hearing problems. Remote programing proved to be of great benefit to our subjects as most of the subjects reported improvement after the teleprograming sessions. Only 6 subjects needed further remote programing for more adjustment. Additionally, the 2 patients who had remote switch on were followed again for further remote programing. A systematic review done by Bush et al. [2016] demonstrated multiple studies that have investigated the delivery of rehabilitative hearing health care in a variety of settings internationally. These studies reported that programing of CIs and hearing aids could be performed through telemedicine effectively and efficiently [Romas, 2009; McElveen, 2010; Wesarg, 2010; Geohring et al., 2012; Hughes et al., 2012; Eikelboom, 2014; Kuzovkov, 2014].

The forth part of the questionnaire focused on the effect of missing the rehabilitation sessions on the children. The parents reported some negative effects due to missing rehabilitation sessions. They reported that the communication skills and ability of engagement in interactive activities were negatively affected during the isolation period. Some of the parents reported that the children behavior have been changed in which way attributed this to the isolation. It was evident from the Ayas et al.'s [2020] study that the present situation is psychologically pressing for both parents and for their children. In their study, parents have reported that home-training activities were difficult, and the child may not be able to cooperate with the task to achieve the target goal assigned by their clinician. Moreover, they faced greater trouble adapting to the remote learning environment. However, our rehabilitation team could benefit from the telehealth technology, and they kept in contact with the patients through video or telephone calls.

\section{Conclusion and Recommendations}

CI patients were affected to some extent during the COVID-19 pandemic. However, telecommunication and telehealth could sustain the continuity of patient care during this pandemic either during the lockdown and stay at home phase or at the phase of distancing to reduce the spread of infection. Additionally, our team became more aware of the requirements of the patients during this situation and could succeed to implement the telehealth to help our patients.

The CI program in KFHU hospital provides services for patients from all different areas of the eastern province (Hafer albaten, alKhafji, alhafofo, al Jubail, and alqatif) which are ranging from 502 to $32 \mathrm{~km}$ away from our hospital. So, this experience encourage the implementation of telecommunication clinics in our unit to overcome the problem of missing appointments and save the families the trouble of driving long distance for their appointments. Last but not least, we encourage all CI programs in the kingdom of Saudi Arabia to adopt this facility to be able to follow their patients without the need to travel which will guarantee the best patient care and benefit from the implants.

\section{Statement of Ethics}

Parents or guardians of the children have given their written informed consent. The study protocol was approved by Imam Abdulrahman Bin Faisal University Institutional Review Board (IRB2020-01-170) prior to subject enrollment.

\section{Conflict of Interest Statement}

The authors declare no conflicts of interest or any commercial relation with the contents of the manuscript.
Telmesani/Said/Mahrous/Alrusayyis 


\section{Funding Sources}

This study was not funded by any governmental or private sponsor.

\section{Author Contributions}

L.M.T.: design of the questionnaire, data collection, and revision the manuscript. N.M.S.: data collection, statistical analysis, data interpretation, and writing of the manuscript. M.M.M.: data analysis and revision of the manuscript. D.F.A.: translation of the questionnaire to Arabic language and contacting the subjects to answer the questionnaire.

\section{References}

Ayas M, Ali Al Amadi AMH, Khaled D, Alwaa AM. Impact of COVID-19 on the access to hearing health care services for children with CIs: a survey of parents. F1000Res. 2020;9:690.

Bokolo A. Use of telemedicine and virtual care for remote treatment in response to COVID-19 pandemic. J Med Sys. 2020;44:132.

Botros A, Banna R, Maruthurkkara S. The next generation of Nucleus ${ }^{\circ}$ fitting: a multiplatform approach towards universal CI management. Int J Audiol. 2013;52:485-94.

Bush ML, Thompson R, Irungu C, Ayugi J. The role of telemedicine in auditory rehabilitation: a systematic review. Otol Neurotol. 2016 Dec;37(10):1466-74.

de Graaff F, Huysmans E, Qazi OU, Vanpoucke FJ, Merkus P, Goverts ST, et al. The development of remote speech recognition tests for adult cochlear implant users: the effect of presentation mode of the noise and a reliable method to deliver sound in home environments. Audiol Neurootol. 2016;21(Suppl 1):48-54.

Eikelboom RH, Jayakody DM, Swanepoel DW, Chang S, Atlas MD. Validation of remote mapping of CIs. J Telemed Telecare. 2014; 20(4):171-7.
Goehring JL, Hughes ML, Baudhuin JL, Valente DL, McCreery RW, Diaz GR, et al. The effect of technology and testing environment on speech perception using telehealth with CI recipients. J Speech Lang Hear Res. 2012;55:1373-86.

Golinelli D, Boetto E, Carullo G, Landini M, Fantini $M$. How the COVID-19 pandemic is favoring the adoptionof digital technologies in healthcare: a rapid literature review. medRxiv. 2020.

Heidi K, Jamie J, Kristin K, Holly T, Lisa R, Allison $\mathrm{B}$, et al. Remote programming of cochlear implants. Otol Neurotol. 2019 Mar;40(3):e260-6.

Hughes ML, Goehring JL, Baudhuin JL, Diaz GR, Sanford T, Harpster R, et al. Use of telehealth for research and clinical measures in CI recipients: a validation study. J Speech Lang Hear Res. 2012;55:1112-27.

Jiang Y, Gu P, Li B, Gao X, Sun B, Song Y, et al. Analysis and management of complications in a cohort of 1,065 minimally invasive cochlear implantations. Otol Neurotol. 2017 Mar;38(3):347-51.

Kuldeep D, Sharun K, Ruchi T, Shubhankar S, Sudipta B, Yashpal SM, et al. Coronavirus disease 2019-COVID-19. Clin Microbiol Rev. 2020 Oct;33(4):e00028-20.
Kuzovkov V, Yanov Y, Levin S, Bovo R, Rosignoli M, Eskilsson G. Remote programming of MED-EL CIs: users' and professionals' evaluation of the remote programming experience. Acta Otolaryngol. 2014;134:709-16.

Matthew L, Bush M, Robin Thompson M, Catherine I, John A. The role of telemedicine in auditory rehabilitation: a systematic review. 2016 Dec;37(10):1466-74.

McElveen JT, Jr, Blackburn EL, Green JD Jr, McLear PW, Thimsen DJ, Wilson BS. Remote programming of CIs: a telecommunications model. Otol Neurotol. 2010;31:1035-40.

Ramos A, Rodríguez C, Martinez-Beneyto P, Perez D, Gault A, Falcon JC, et al. Use of telemedicine in the remote programming of CIs Acta Otolaryngol. 2009;129:533-40.

Shapiro WH, Huang T, Shaw T, Roland JT Jr, Lalwani AK. Remote intraoperative monitoring during CI surgery is feasible and efficient. Otol Neurotol. 2008;29:495-8.

Truy E, Gallego S, Chanal JM, Collet L, Morgon A. Correlation between electrical auditory brainstem response and perceptual thresholds in Digisonic CI users. Laryngoscope. 1998;108:554-9.

Wesarg T, Wasowski A, Skarzynski H, Ramos A, Falcon Gonzalez JC, Kyriafinis G, et al. Remote fitting in Nucleus CI recipients. Acta Otolaryngol. 2010;130:1379-88. 